\title{
Thermal Simulation of Grain During Selective Laser Melting Process in 3D Metal Printing
}

\author{
Numan Habib ${ }^{1 *}$, Muftooh Ur Rehman Siddiqi ${ }^{1}$ and Riaz Muhammad ${ }^{2}$ \\ ${ }^{1}$ CECOS University of IT and Emerging Sciences, Peshawar, Khyber Pakbtunkhwa, Pakistan; ${ }^{2}$ University of Bahrain, College \\ of Engineering, Bahrain.
}

Abstract: In this paper, effect of laser scanning speed and grain size of powder of three different materials
Aluminum 7075, AM100A Magnesium and UNS C 85500 yellow brass are investigated. A Gaussian
distribution type laser having 100 -watt power and $100 \mathrm{~m}$ spot size is used. Simulation is carried out on a
single grain, directly exposed to the laser. The prime goal of this study is to investigate the effect of different
process parameters on temperature distribution in grain and capability of the specified laser to melt and
fuse above mentioned material powder grain. Three different $2 \mathrm{D}$ models of $1 \mu \mathrm{m}, 2 \mu \mathrm{m}$ and $3 \mu \mathrm{m}$ grain sizes
are modeled and simulated with different scanning speed $60,100,140,180$ and $220 \mathrm{~mm} / \mathrm{sec}$. Results are
demonstrated for thermal distribution on grain along the depth. Center of the lower surface of the grain is
chosen as a focus point and values are recorded and compared. The simulation results are in good agreement
with the experimental work conducted in literature. For $1 \mu \mathrm{m}$ grain size melting of aluminum 7075 and
AM100A Magnesium is achieved with all scanning speed except UNS C85500 Yellow Brass.
Received: January 13, 2020; Accepted: June 19,2020; Published: December 19, 2020
*Correspondence: Numan Habib, CECOS University of IT and Emerging Sciences, Peshawar, Khyber Pakhtunkhwa, Pakistan; Email:
numanhabib@cecos.edu.pk
Citation: Habib, N., M.U.R. Siddiqi and R. Muhammad. 2020. Thermal simulation of grain during selective laser melting process in 3D metal
printing. Journal of Engineering and Applied Sciences, 39(2): $127-134$.
DOI: http://dx.doi.org/10.17582/journal.jeas/39.2.127.134
Keywords: Selective laser melting, Laser, 3D printing, Metal 3d printing, SLM process, SLM simulation

\section{Introduction}

Selective laser melting is an additive manufacturing technique in which part is produced layer by layer using data extracted from the 3D model through specialized software (Zhang et al., 2017). Additive Manufacturing is bottom up manufacturing approaches opposed to subtractive manufacturing usually known as top down manufacturing approach to producing parts (Bingheng et al., 2013; Li et al., 2013). This process does not require any specialized tools or jig and fixtures like conventional machining operations. Hence, making this approach economical to produce customized and even more complex parts (Zhang et al., 2017). Advancement in laser technology and development of high-power lasers made it possible to create customize and high-performance parts using this technology. Due to numerous advantages and manufacturing flexibility, this approach is widely used in many industries, such as an automobile, aerospace, military and medical industries (Caiazzo et al. 2013; Wang, 2014; Yan et al., 2015).

Selective laser melting process belongs to additive manufacturing process which use high power laser to melt powder grains and fuse them together to create complex geometries. This technique is used in 3D metal printers to print complex geometries. Power of laser, grain size, scanning speed and material properties have great influence on the melting process 
of powder grains. Hence, effects the strength of 3D printed finished part.

In past, a lot of research work is done in this area to investigate selective laser melting process. For example, simulation and experimental work have been carried out to study the effect of laser parameters on steel properties (Syarifah et al., 2012). Quality of the part produced during selective laser melting strongly depends upon operating temperature, which is usually controlled by processing variables (Song et al., 2012). High scanning speed increase length of melt pool. However, depth and width of the pool reduce (Hussein et al., 2013). Quality of the selective laser melted part is directly related to the density achieved after melting and solidification process. During solidification, gaseous bubbles traps in the melted pool and decrease the quality of the part. Previously, researchers have investigated that with an optimized linear energy density of $17.5 \mathrm{~kJ} / \mathrm{m}$, bubbles trapped in the melted pool is removed and up-to $96 \%$ density of the powder after laser processing is achieved (Dai et al., 2014).

A lot of simulations and experiments have been done to study energy input through laser into powder grains for different process variables by comparing melting pools depth and width, and temperature distribution in the layer (Riedlbauer et al., 2014). The size (depth and width) of the melt pool varies from the start of the track to the end of the track. Similarly, the size changes from track to track. After few tracks the condition becomes stable and the size of melt pool becomes constant (Foroozmehr et al., 2016).

Other researchers in past, worked on thermal simulation of different materials (specifically steel) to investigate the surface heating of powder grain for different process parameters (Li et al., 2004; Yilbas et al. 2007). Though, researchers have focused their studies on ceramic coatings (Singh et al., 1996; Peligrad et al., 2001).

In SLM processes defects formation such as cracks, porosities, and incomplete fusion holes during melting and solidification of grains in fusion bed has been studied in the past (Gong et al., 2014; Carter et al., 2015; Read et al., 2015; Zhou et al., 2015). Researchers have done a lot of simulation and conducted experiments to understand defect formation mechanism in selective laser melting process. New techniques were developed to overcome the problem and enhance mechanical properties of 3D printed parts (Clijsters et al., 2014). Quality of the 3D printed part greatly depends on selecting of suitable laser power, scanning speed, material, and grain size. All these parameters have a great effect on temperature distribution in powder bed (Zeng et al., 2012). In many highly developed countries like Germany, Sweden, China and USA etc. 3D metal printing with SLM technique is used for aerospace manufacturing and medical implants (Rahim and Maidin, 2014; Yadroitsev et al., 2015; Ren et al., 2016; Bartlett et al., 2018). like Lack of laser power compatibility data with different material made it difficult to choose appropriate laser for 3D printers to achieve melting of specific metals and fuse them together to create $3 \mathrm{D}$ parts layer by layer. In this paper compatibility of 100 watt $\mathrm{Nd}$ :Yag continuous laser with three different materials Aluminum 7075, AM100A Magnesium and UNS-C85500 is studied. These materials are used commonly in many industries because of their physical and thermal properties. Simulations have been done to study temperature distribution in grain at various scanning speeds and grain sizes. Also, the relation of process parameters with temperature is investigated.

\section{Materials and Methods}

Effects of different parameters are studied on melting of powder grain in previous observations. Based on these studies process variable is identified. The simulation is designed according to the number of process variables to collect maximum data which helps in understanding the behavior of different process parameters and relationships with each other. Modeling is done and simulation is performed 15 times for each material with different process parameters through ANSYS Parametric Design Language 17.0. Model is validated with experimental data in literature.

\section{Process parameters}

$\mathrm{Nd}$ :Yag continuous laser, Gaussian distribution type laser is used for the analysis. The specified laser specification is shown in Table 1 . The laser is used as thermal energy source. The moving laser heated the surface of the grain for specific time according to the scanning speed. The heat transfer to the grain increases the temperature and melt it. 
Table 1: Laser specification used for melting (Foroozmehr et al., 2016).

$\begin{array}{ll}\text { Laser power } & 220 \text { Watt } \\ \text { Laser type } & \text { Gaussian distribution } \\ \text { Spot size } & 100 \mu \mathrm{m}\end{array}$

Three different materials shown in Table 2 are chosen for analysis. These materials have a different melting temperature, density, thermal conductivity and specific heat capacity. All these parameters accounts for the temperature difference in the targeted zone.

In (Jian et al., 2010; Yin et al., 2012) the impact of powder material and scanning speed is investigated. The study showed that the strength of $3 \mathrm{D}$ printed part highly dependent on the above-mentioned parameters. In this paper, these process variables are chosen to study its effect on thermal distribution across powder grain (Table 3). The effect of chosen variables on thermal distribution is simulated for three different values of scanning speeds, grain sizes, and material properties.

\section{Model development and validation}

$2 \mathrm{D}$ model of $1 \mu \mathrm{m}, 2 \mu \mathrm{m}$, and $3 \mu \mathrm{m}$ diameters single grain is modeled in Mechanical ANSYS Parametric Design Language 17.0. Grain of the above-mentioned diameters are modeled for each material. The 2D shape of the grain is simple. Hence, the free mesh is created and refined through APDL meshing tool.

Table 2: Properties of materials used in the analysis.

$\begin{array}{llll}\text { Material } & \begin{array}{l}\text { Aluminum } \\ \mathbf{7 0 7 5}\end{array} & \begin{array}{l}\text { AM100A } \\ \text { Magnesium }\end{array} & \begin{array}{l}\text { UNS-C85500 } \\ \text { Yellow brass }\end{array} \\ \begin{array}{l}\text { Melting tempera- } \\ \text { ture (K) }\end{array} & 913 & 703 & 1173 \\ \begin{array}{l}\text { Density (Kg/mm3) } \\ \text { 0.281 }\end{array} & 0.17 & 0.8 \\ \begin{array}{l}\text { Thermal conductiv- } \\ \text { ity (W/mm-K) }\end{array} & 0.13 & 0.12 \\ \begin{array}{l}\text { Specific heat }(\mathrm{J} / \\ \text { Kg-K) }\end{array} & 960 & 990 & 390\end{array}$

Table 3: Variables chosen for analysis (Jian et al., 2010; Yin et al., 2012).

Powder material Aluminum 7075, AM100A Magnesium, UNS-C 85500 Yellow Brass

Grain size $\quad 1 \mu \mathrm{m}, 2 \mu \mathrm{m}, 3 \mu \mathrm{m}$

Scanning speed $\quad 60,100,140,180,220 \mathrm{~mm} / \mathrm{sec}$
The initial condition is applied to each node except nodes lies in the upper surface of the model. The initial temperature of the grain is taken $25 \mathrm{C}$ (Room temperature). Thermal load of $2200 \mathrm{C}$ (boundary condition) is applied on the upper surface of $2 \mathrm{D}$ grain model, where the laser is targeted. Heat is generated on the upper surface of the grain due to thermal load and flows down with specific rate through conduction according to material properties. Heat loss through radiation and convection is assumed to be zero. Simulation is performed for 45 different cases for three different materials with different process parameters.

The simulation is transient and depends on simulation time (Scanning speed). Hence, time is calculated for each scanning speed using Equation 1 and shown in Table 4. Data is recorded for all three materials at a specified point of the grain shown in Table 5. And results of each simulation is plotted along the depth of the grain.

Table 4: Simulation time.

\begin{tabular}{llll} 
Material & $\begin{array}{l}\text { Scanning speed } \\
(\mathbf{m m} / \mathbf{s e c})\end{array}$ & $\begin{array}{l}\text { Simulation } \\
\text { time }(\mathbf{s e c})\end{array}$ & $\begin{array}{l}\text { Grain size } \\
(\boldsymbol{\mu m})\end{array}$ \\
\hline $\begin{array}{l}\text { Aluminum } \\
7075\end{array}$ & 60 & 0.016 & 1,2 and 3 \\
& 100 & 0.01 & \\
& 140 & 0.0071 & \\
& 180 & 0.0055 & \\
& 220 & 0.0045 & \\
AM100A & 60 & 0.016 & \\
Magnesium & 100 & 0.01 & \\
& 140 & 0.0071 & 0.0055 \\
& 180 & 0.0045 \\
UNS & 220 & 0.016 \\
C85500 & 60 & 0.01 \\
Yellow Brass & 100 & 0.0071 \\
& 140 & 0.0055 \\
& 180 & 0.0045 \\
& 220 &
\end{tabular}

Simulation time is calculated using Equation 1 (Zhang et al., 2017):

$$
T=V / d \quad \ldots(1)
$$

" $\mathrm{d}$ " is the diameter of the laser beam in $\mathrm{mm}$. Whereas " $\mathrm{v}$ " is scanning speed in $\mathrm{mm} / \mathrm{sec}$ and " $\mathrm{T}$ " is total time of simulation. Simulation time express the duration of grain expose to the laser beam. As the scanning

December 2020 | Volume 39 | Issue 2 | Page 129 
speed increases the simulation time decrease. While greater spot size of the laser increases the simulation time.

Figure 1 depicts simulation steps during SLM process. The grey grain is taken in focus to understand simulation time. Simulation time is associated with laser scanning speed. Both parameters are inversely proportional to each other. Increase in scanning speed leads to decrease grain exposure time to the laser beam. In this study, scanning speed is converted into simulation time and the laser is assumed to be at rest.

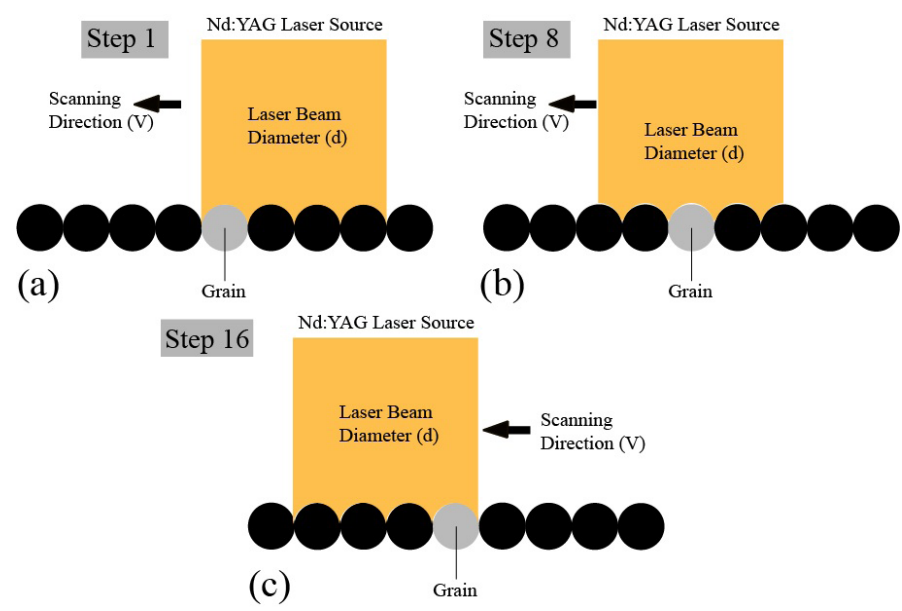

Figure 1: Shows the simulation setup (a) step 1/16 (b) step 8/16 (c) step 16/16.

Initially the model is used to validate (Yan et al., 2015) work, which shows good agreement between the simulation results and experimentally published results. The model is later on used to investigate relation between the process parameters for the mentioned three alloys. The results show good agreement between experimental and simulation results for the given parameters $(\mathrm{v}=20,30,50,80$, 110 and $140 \mathrm{~mm} / \mathrm{sec}, \mathrm{d}=0.05 \mathrm{~mm}$ ) (Bartlett et al., 2018) (Figure 3).
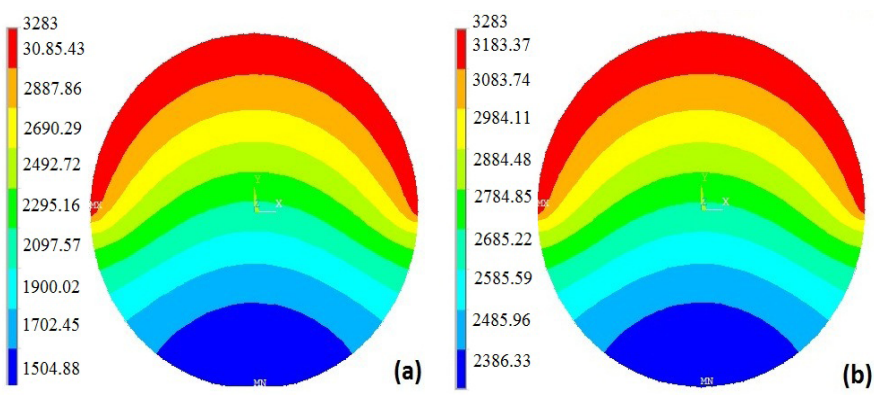

Figure 2: (a) Peak temperature and temperature distribution in nickel (b) Peak temperature and temperature distribution in tungsten.

Further, at $110 \mathrm{~mm} / \mathrm{sec}$ scanning speed simulation shows $3283^{\circ} \mathrm{C}$ maximum temperature in the powder bed surface (Figure 2). However, melting temperature of tungsten and nickel is $3420^{\circ} \mathrm{C}$ and $1453^{\circ} \mathrm{C}$, respectively. Hence, complete melting of tungsten is not achieved which is a major component and accounts for $90 \%$ of the total percentage.

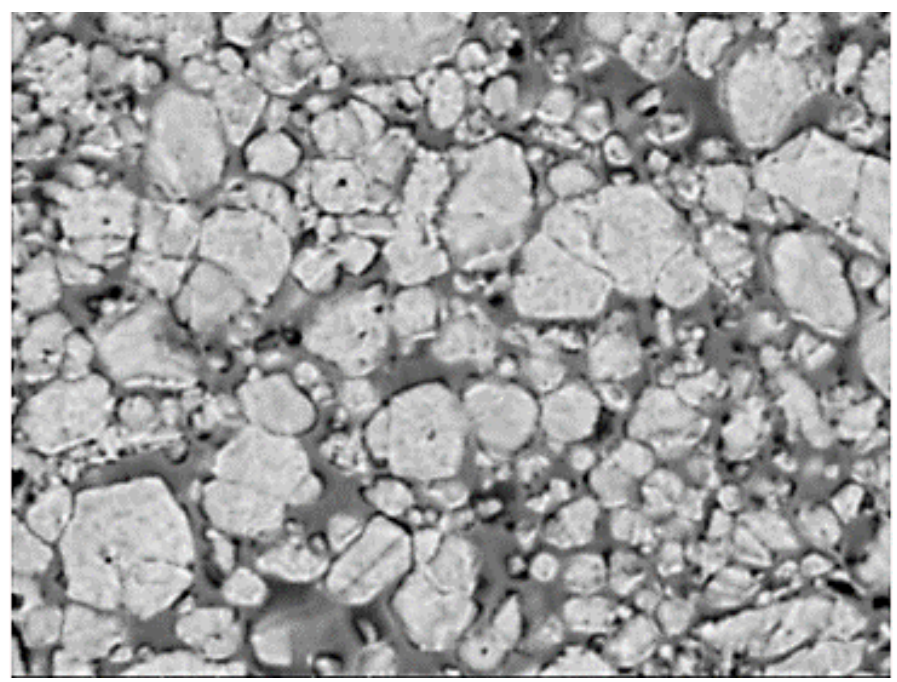

Figure 3: Comparison of curves achieved in (Zhang et al., 2010) and the current study.

Figure 4 shows the microstructure of the fabricated part with 100-watt laser power, $0.05 \mathrm{~mm}$ laser diameter and $110 \mathrm{~mm} / \mathrm{sec}$ scanning speed. The presence of unmelted cellular shape tungsten particles uncovered that the temperature has not reached the melting temperature of tungsten. Therefore, the simulated maximum temperature of $3283^{\circ} \mathrm{C}$ could represent the experimental study.

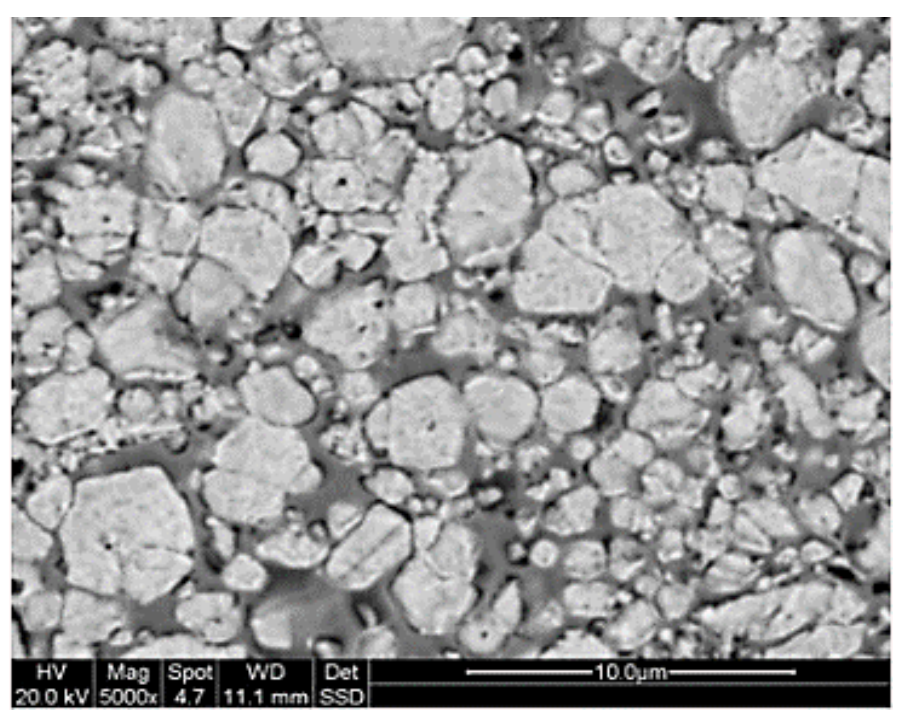

Figure 4: $S E M$ samples at vertical section at $v=110 \mathrm{~mm} / \mathrm{sec}, d=$ $0.05 \mathrm{~mm}, p=100$ watt (Yan et al., 2015).

\section{Results and Discussion}

Figure 5 shows nodal temperature distribution of $1 \mu \mathrm{m}$ 
diameter powder grain for Aluminum 7075 alloy. The grain is exposed to the laser beam for 0.016 seconds (60 $\mathrm{mm} / \mathrm{sec}$ scanning speed). The whole simulation is divided into 16 steps. Step size is defined on the bases of time. Each step has 1 milliseconds duration. Small step size helps better understand the heat flow and temperature distribution in grain. In simulation, 1 milliseconds duration is enough to understand temperature behavior. Figure 5 shows last step results of the simulation, through which melted area of the grain can be observed. In SLM process melting occurs when the temperature increases and meet the melting point of the grain material. Melted portion of the grain flows down and mixed with neighbor grain and fuse together.

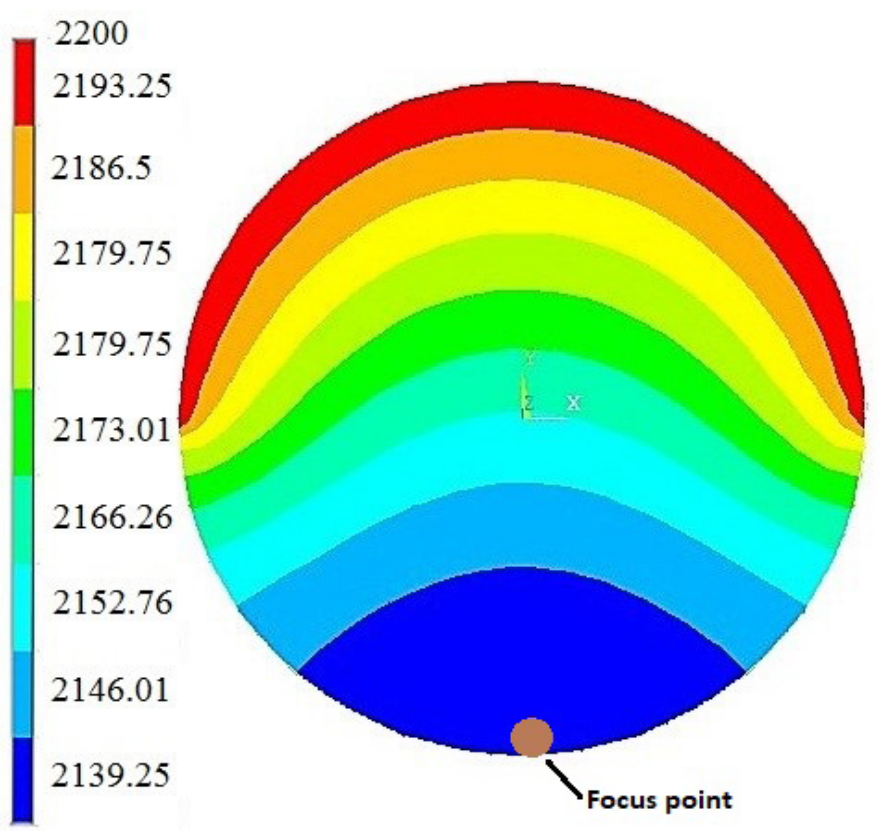

Figure 5: Temperature distribution on $1 \mu m$ powder grain of Aluminum 7075 at $60 \mathrm{~mm} / \mathrm{sec}$ scanning speed.

The temperature value is recorded at a targeted point which is located on the very lower surface of the grain. For successful melting of grain, the temperature at this point must exceed melting temperature of the material. Figure 6 shows temperature at focus point for $1 \mu \mathrm{m}$ grain and scanning speed of $60,100,140$, 180 and $220 \mathrm{~mm} / \mathrm{sec}$. From $1 \mathrm{~mm} / \mathrm{sec}$ up to 180 $\mathrm{mm} / \mathrm{sec}$ temperature in the focused region is above the melting point of all three materials, which will lead to melt down the grain in powder bed during SLM process and fuse them together to form 3D parts. While for UNS-C85500 yellow brass at 220 $\mathrm{mm} / \mathrm{sec}$ temperature is less than its melting point. However, the temperature exceeded form its melting point for aluminum 7075 and AM100A magnesium at same scanning speed. Due to different thermal and physical properties of the materials, the temperature difference can be seen.

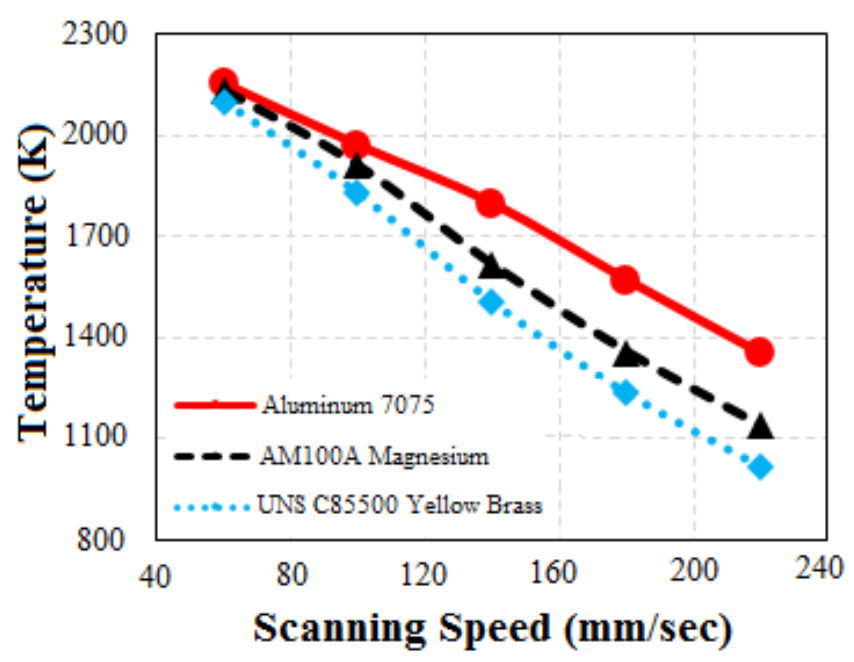

Figure 6: The temperature at the focus point of $1 \mu \mathrm{m}$ diameter grain.

As temperature increases from $60 \mathrm{~mm} / \mathrm{sec}$ to 220 $\mathrm{mm} / \mathrm{sec}$ the difference between the values increases. At a low scanning, speed grain exposes to the laser for a long time and due to low depth of the grain, heat conducts immediately and the difference between the values is small. However, short time of exposure does not allow the heat to conduct efficiently and little amount of heat flows to the lower surface of the grain. Values difference at high scanning speeds depends upon the thermal and physical properties of materials.

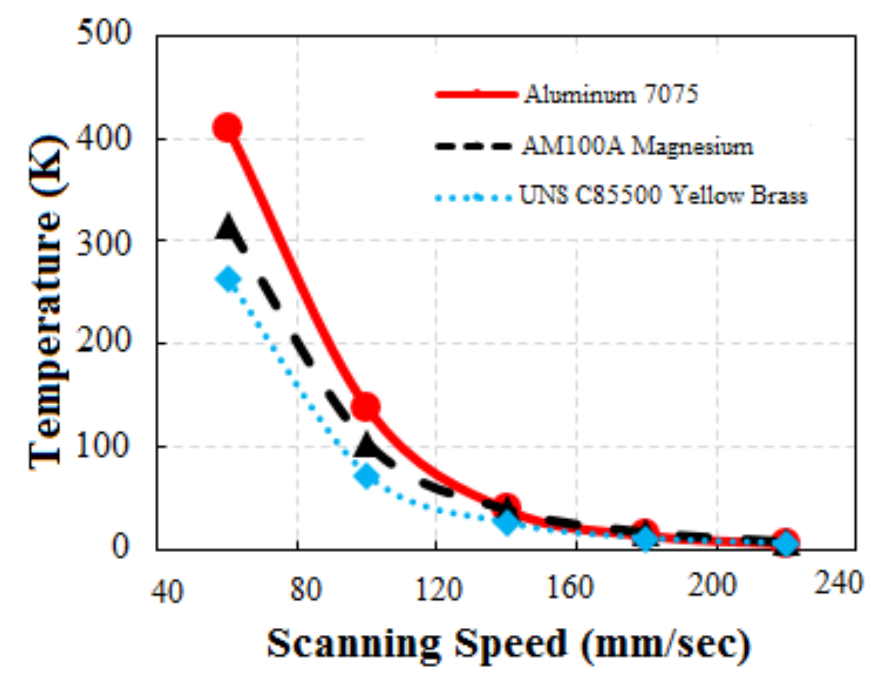

Figure 7: The temperature at the focus point of $2 \mu \mathrm{m}$ diameter grain.

For $2 \mu \mathrm{m}$ grain diameter temperature and scanning speed relation are shown in Figure 7. The temperature at the lower surface of the aluminum 7075 and AM100A magnesium grain surpassed its melting point till approximately $70 \mathrm{~mm} / \mathrm{sec}$. Above this scanning speed, the temperature for both alloys is 
less than its melting point. However, the simulation predicted temperature less than the melting temperature of UNS-C 85500 yellow brass at $60 \mathrm{~mm} /$ sec and above this scanning speed at targeted region.

Figure 8 shows temperature for all three alloys at a different speed and $3 \mu \mathrm{m}$ grain size. For all scanning speed, melting temperature is not achieved at the lower surface of the grain. Hence, complete melting of the grain is not achieved. Melting temperature for aluminum 7075, AM100A magnesium and UNS-C85500 yellow brass is $913 \mathrm{~K}, 703 \mathrm{~K}$, and 1173 $\mathrm{K}$, respectively.

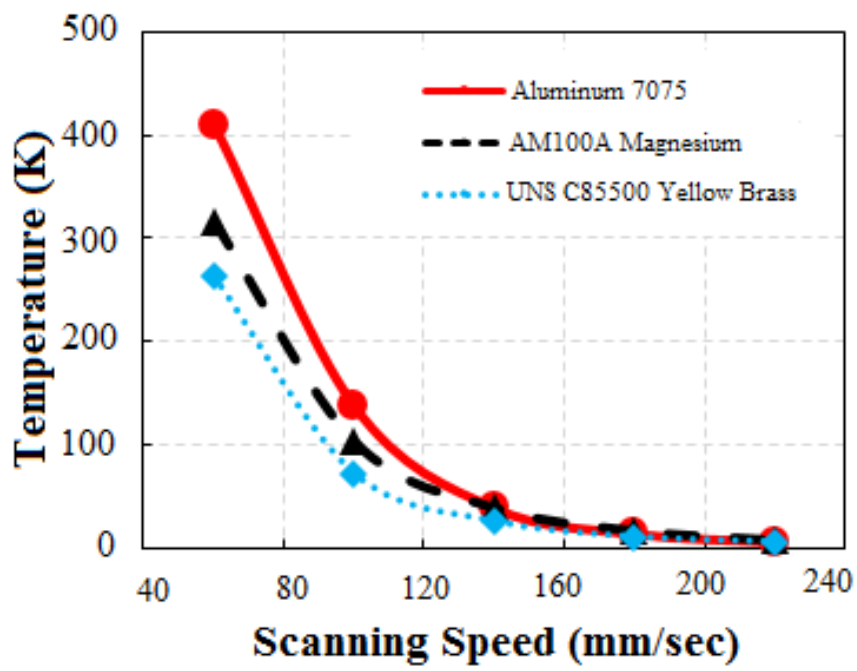

Figure 8: The temperature at the focus point of $3 \mu \mathrm{m}$ diameter grain.

Table 5: Temperature at a targeted point.

$\begin{array}{lllll}\begin{array}{l}\text { Scanning Grain } \\ \text { speed } \\ (\mathbf{m m} / \mathbf{s})\end{array} & \begin{array}{l}\text { Aluminum } \\ \text { size } \\ (\boldsymbol{\mu m})\end{array} & \begin{array}{l}\text { AM100A Mag-e } \\ \text { Celsius) }\end{array} & \begin{array}{l}\text { UNS } \\ \text { nesium (Degree }\end{array} \\ & & & \begin{array}{l}\text { Us5500 Yel- } \\ \text { Cew (Degree } \\ \text { Celsius) }\end{array} \\ 60 & & 2139 & 2131 & 2098 \\ 100 & & 1969 & 1908 & 1827 \\ 140 & 1 & 1797 & 1614 & 1504 \\ 180 & & 1570 & 1356 & 1235 \\ 220 & & 1352 & 1137 & 1016 \\ 60 & & 1195 & 1091 & 945 \\ 100 & & 682 & 584 & 480 \\ 140 & 2 & 393 & 323 & 253 \\ 180 & & 240 & 190 & 143 \\ 220 & & 157 & 121 & 88 \\ 60 & & 410 & 315 & 264 \\ 100 & & 137 & 103 & 72 \\ 140 & 3 & 38 & 39 & 25 \\ 180 & & 13 & 17 & 10 \\ 220 & & 5 & 8 & 5\end{array}$

The graphs shown in both Figures 7 and 8 have the same behavior. When scanning speed increases the temperature and difference between all three materials at targeted point decrease. However, at low scanning speed and high exposure duration of grain to the laser, maximum heat is allowed to conduct along the depth of the grain. Due to high $(2 \mu \mathrm{m}$ and $3 \mu \mathrm{m})$ thickness, minimum heat flows through the depth of grain. Physical and thermal properties account for the temperature difference. When initially laser falls on the grain, the surface exposed to laser absorb energy and increase the temperature of the area. At this time temperature difference between upper and lower surface is maximum. And heat flows from the top surface to bottom surface with the maximum rate. However, the rate of heat flow decreases when temperature difference drops. So, for high scanning speed little amount of energy transfers to the bottom and difference of temperature at targeted region declines.

\section{Conclusions and Recommendations}

Thermal simulation of different sizes of grain for different materials and scanning speeds is carried out and following are the major conclusions.

1. Scanning speed and temperature have inversely proportional. At low scanning speed, the grain surface exposed to the laser for long duration and laser energy input to the grain is high which tends to increase temperature.

2. The specified laser is capable to print $3 \mathrm{D}$ parts using Aluminum 7075 and AM100A Magnesium powder with scanning speed ranges from $1 \mathrm{~mm} /$ sec to $220 \mathrm{~mm} / \mathrm{sec}$ for grain diameter of $1 \mu \mathrm{m}$. While UNS C85500 yellow brass powder can be used with scanning speed from 1 to $180 \mathrm{~mm} / \mathrm{sec}$.

3. For $2 \mu \mathrm{m}$ grain size, the laser is capable to melt Aluminum 7075 and AM100A Magnesium powder only with $60 \mathrm{~mm} / \mathrm{sec}$ and below this scanning speed up-to $1 \mathrm{~mm} / \mathrm{sec}$. While melting of UNS C85500 yellow brass powder cannot be achieved with an identified laser for any scanning speed.

4. With grain size of $3 \mu \mathrm{m}$, the laser does not have the capability to melt Aluminum 7075, AM100A Magnesium and UNS C85500 yellow brass powder even for the lowest scanning speed i.e. 60 $\mathrm{mm} / \mathrm{sec}$. 


\section{Novelty Statement}

In this research project, the melting capability of $\mathrm{Nd}$ : Yag continuous laser for Aluminum 7075, AM100A Magnesium and UNS C85500 yellow brass is investigated.

\section{Author's Contribution}

Numan Habib: Conceptualization, development, modeling, simulation, analysis and paper writing.

Muftooh Ur Rehman Siddiqi: Supervision, provided guidelines and delivered resources.

Riaz Muhammad: Supervision in writing.

\section{Confict of interest}

The authors have declared no conflict of interest.

\section{References}

Bartlett, J.L., B.P. Croom, J. Burdick, D. Henkel and X.J.A.M. Li. 2018. Revealing mechanisms of residual stress development in additive manufacturing via digital image correlation. 22: 1-12. https://doi.org/10.1016/j. addma.2018.04.025

Bingheng, L., L.J.M.B. Dichen and Automation. 2013. Development of the additive manufacturing (3D printing) technology. 4: 001.

Caiazzo, F., F. Cardaropoli, V. Alfieri, V. Sergi and L. Cuccaro. 2013. Experimental analysis of selective laser melting process for $\mathrm{Ti}$ $6 \mathrm{Al}-4 \mathrm{~V}$ turbine blade manufacturing. XIX International symposium on high-power laser systems and applications 2012, International Society for Optics and Photonics. https://doi. org/10.1117/12.2010577

Carter, L.N., K. Essa and M.M. Attallah. 2015. Optimisation of selective laser melting for a high temperature Ni-superalloy. https://doi. org/10.1108/RPJ-06-2013-0063

Clijsters, S., T. Craeghs, S. Buls, K. Kempen and J.P. Kruth. 2014. In situ quality control of the selective laser melting process using a highspeed, real-time melt pool monitoring system. 75(5-8): 1089-1101. https://doi.org/10.1007/ s00170-014-6214-8

Dai, D., D.J.M. Gu and Design. 2014. Thermal behavior and densification mechanism during selective laser melting of copper matrix composites: Simulation and experiments. 55: 482-491. https://doi.org/10.1016/j. matdes.2013.10.006

Foroozmehr, A., M. Badrossamay, E. Foroozmehr, S.i.J.M. Golabi and Design. 2016. Finite element simulation of selective laser melting process considering optical penetration depth of laser in powder bed. 89:255-263. https://doi. org/10.1016/j.matdes.2015.10.002

Gong, H., K. Rafi, H. Gu, T. Starr and B.J.A.M. Stucker. 2014. Analysis of defect generation in Ti-6Al-4V parts made using powder bed fusion additive manufacturing processes. 1: 87-98. https://doi.org/10.1016/j.addma.2014.08.002

Hussein, A., L. Hao, C. Yan, R.J.M. Everson and Design. 2013. Finite element simulation of the temperature and stress fields in single layers built without-support in selective laser melting. 52: 638-647. https://doi.org/10.1016/j. matdes.2013.05.070

Jian, Z., L. Deying, Z. Longzhi and Z. Mingjuan. 2010. Simulation of temperature field in selective laser sintering of copper powder. 2010 International Conference on Mechanic Automation and Control Engineering, IEEE.

Li, D., J. He, X. Tian, Y. Liu, A. Zhang, Q. Lian, Z. Jin and B.J.J.G.X. Lu. 2013. Additive manufacturing: Integrated fabrication of macro/microstructures. 49(6): 129-135. https:// doi.org/10.3901/JME.2013.06.129

Li, J., L. Li and F.J.A.M. Stott. 2004. Thermal stresses and their implication on cracking during laser melting of ceramic materials. 52(14): 4385-4398. https://doi.org/10.1016/j. actamat.2004.06.005

Peligrad, A., E. Zhou, D. Morton, L.J.O. Li and L. Technology. 2001. A melt depth prediction model for quality control of laser surface glazing of inhomogeneous materials. 33(1): 7-13. https://doi.org/10.1016/S00303992(00)00107-9

Rahim, S.L. and S. Maidin. 2014. Feasibility study of additive manufacturing technology implementation in Malaysian automotive industry using analytic hierarchy process. Advanced Materials Research, Trans Tech Publ. https://doi.org/10.4028/www.scientific. net/AMR.903.450

Read, N., W. Wang, K. Essa, M.M.J.M. Attallah and Design. 2015. Selective laser melting of AlSi10Mg alloy: Process optimisation 
and mechanical properties development. 65: 417-424. https://doi.org/10.1016/j. matdes.2014.09.044

Ren, X., H. Shao, T. Lin, H.J.M. Zheng and Design. 2016. 3D gel-printing. An additive manufacturing method for producing complex shape parts. 101: 80-87. https://doi. org/10.1016/j.matdes.2016.03.152

Riedlbauer, D., M. Drexler, D. Drummer, P. Steinmann and J.J.C.M.S. Mergheim. 2014. Modelling, simulation and experimental validation of heat transfer in selective laser melting of the polymeric material PA12. 93: 239-248. https://doi.org/10.1016/j. commatsci.2014.06.046

Singh, J., B. Bhat, R. Poorman, A. Kar, J.J.S. Mazumder and C. Technology. 1996. Laser glazing of vacuum plasma spray coated NARloy-Z., $\quad 79(1-3): \quad 35-49 . \quad$ https://doi. org/10.1016/0257-8972(95)02441-7

Song, B., S. Dong, H. Liao and C. Coddet. 2012. Process parameter selection for selective laser melting of Ti6Al4V based on temperature distribution simulation and experimental sintering. 61(9-12): 967-974. https://doi. org/10.1007/s00170-011-3776-6

Syarifah, N.A.S.A., S. Naher and D. Brabazon. 2012. Thermal simulation of laser surface modification of H13 die steel. Key Engineering Materials, Trans Tech Publ.,

Wang, H.M., 2014. Materials' fundamental issues of laser additive manufacturing for highperformance large metallic components. 35(10): 2690-2698.

Yadroitsev, I., I.J.V. Yadroitsava and P. Prototyping. 2015. Evaluation of residual stress in stainless steel 316L and Ti6Al4V samples produced by selective laser melting. 10(2): 67-76. https://doi. org/10.1080/17452759.2015.1026045

Yan, C., L. Hao, A. Hussein and P. Young. 2015. Ti-6Al-4V triply periodic minimal surface structures for bone implants fabricated via selective laser melting. 51: 61-73. https://doi. org/10.1016/j.jmbbm.2015.06.024

Yilbas, B., A. Arif, C. Karatas and M.J.A.S.S. Ahsan. 2007. Cemented carbide cutting tool: Laser processing and thermal stress analysis. 253(12): 5544-5552. https://doi.org/10.1016/j. apsusc.2006.12.123

Yin,J.,H.Zhu,L.Ke,W.Lei, C.Dai and D.J.C.M.S. Zuo. 2012. Simulation of temperature distribution in single metallic powder layer for laser micro-sintering. 53(1): 333-339. https:// doi.org/10.1016/j.commatsci.2011.09.012

Zeng, K., D. Pal and B. Stucker. 2012. A review of thermal analysis methods in laser sintering and selective laser melting. Proceedings of Solid Freeform Fabrication Symposium Austin, TX.

Zhang, B., Y. Li and Q. Bai. 2017. Defect formation mechanisms in selective laser melting: A review. 30(3): 515-527. https://doi.org/10.1007/ s10033-017-0121-5

Zhang, D., Q. Cai, J. Liu, L. Zhang and R.D. Li. 2010. Select laser melting of $\mathrm{W}-\mathrm{Ni}-\mathrm{Fe}$ powders: Simulation and experimental study. 51(5-8): 649-658. https://doi.org/10.1007/s00170-0102641-3

Zhou, X., D. Wang, X. Liu, D. Zhang, S. Qu, J. Ma, G. London, Z. Shen and W.J.A.M. Liu. 2015. 3D-imaging of selective laser melting defects in a $\mathrm{Co}-\mathrm{Cr}-\mathrm{Mo}$ alloy by synchrotron radiation micro-CT. 98: 1-16. https://doi.org/10.1016/j. actamat.2015.07.014 